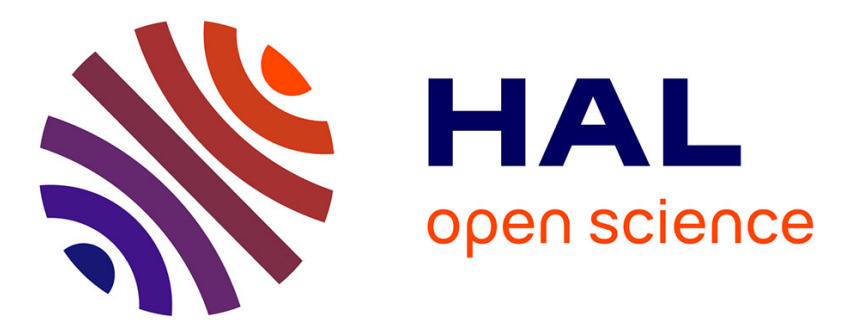

\title{
Measurement and modelling of NO fluxes over maize and wheat crops during their growing seasons: effect of crop management
}

P. Laville, C. Hénault, B. Gabrielle, Dominique Serça

\section{- To cite this version:}

P. Laville, C. Hénault, B. Gabrielle, Dominique Serça. Measurement and modelling of NO fluxes over maize and wheat crops during their growing seasons: effect of crop management. Nutrient Cycling in Agroecosystems, 2005, 72 (2), pp.159-171. 10.1007/s10705-005-0510-5 . hal-00023220

\author{
HAL Id: hal-00023220 \\ https://hal.science/hal-00023220
}

Submitted on 11 Aug 2021

HAL is a multi-disciplinary open access archive for the deposit and dissemination of scientific research documents, whether they are published or not. The documents may come from teaching and research institutions in France or abroad, or from public or private research centers.
L'archive ouverte pluridisciplinaire HAL, est destinée au dépôt et à la diffusion de documents scientifiques de niveau recherche, publiés ou non, émanant des établissements d'enseignement et de recherche français ou étrangers, des laboratoires publics ou privés.

\section{(c)(1)}

Distributed under a Creative Commons Attribution| 4.0 International License 


\title{
Measurement and modelling of NO fluxes on maize and wheat crops during their growing seasons: effect of crop management
}

\author{
P. Laville ${ }^{1, *}$, C. Hénault ${ }^{2}$, B. Gabrielle ${ }^{1}$ and D. Serça ${ }^{3}$ \\ ${ }^{1}$ INRA, Unité Environnement et Grandes Cultures, Thiverval-Grignon, France; ${ }^{2} I N R A$, UMR INRA- \\ Université de Bourgogne Microbiologie et Géochimie des Sols, Dijon, France; ${ }^{3}$ Laboratoire d'Aérologie, \\ Université Paul Sabatier, Toulouse, France; *Author for correspondence (UMR INRA INA P-G Environn- \\ ement et Grandes Cultures, 78850 Thiverval-Grignon, France; e-mail: laville@grignon.inra.fr; fax: + 33-1-30- \\ 81-55-63)
}

Key words: Arable soils, Biogenic, Influencing factors, Modelling, NO emission

\begin{abstract}
Fertilized agricultural soils are a significant source of NO, a gas involved in tropospheric ozone formation. The aims of the research reported here were to measure NO fluxes over the length of the growing season of wheat and maize crops, and to build a model of soil NO emissions from arable land. Field experiments were carried out on a 1-ha field divided into two parts. The first one was cropped with wheat and harvested in late July, 2002, whereas the second part was sown with maize and harvested in October. The wheat and maize received $130 \mathrm{~kg} \mathrm{~N}^{-1}$ and $140 \mathrm{~kg} \mathrm{~N}^{-1}$, respectively. For each crop, NO fluxes were measured during 10 months every 2 weeks using manual closed chambers, and continuously with a wind tunnel immediately after nitrogen fertilization. Fertilizer application significantly affected NO emissions: the largest NO emissions were recorded a few days after nitrogen application. This delay depended on the kinetics of nitrogen incorporation in the soil, as influenced by rainfall. The emissions measured on the maize field $(2.6 \%$ of the fertilizer amount applied) were more important than those on the wheat field $(1.0 \%$ of the fertilizer amount applied), owing to differences in timing of nitrogen application, with respect to climate and crop growth. Relationships between soil nitrification rate and NO emission obtained from laboratory incubations, and experimental data appeared useful and relevant to predict NO emissions at the field-scale.
\end{abstract}

\section{Introduction}

Nitrogen oxides $\left(\mathrm{NO}_{x}=\mathrm{NO}+\mathrm{NO}_{2}\right)$ play a central role in the tropospheric photochemistry leading to ozone formation. Because of the potential damage of ozone on plants, human health and climate, the emissions of $\mathrm{NO}_{x}$ are of considerable concern. In terms of global source strength, biogenic emissions from soils are highly uncertain, with global estimates ranging between 5.5 and 21 Tg N (Yienger and Levy 1995; Davidson 1991), and accounting for up to $40 \%$ of the global $\mathrm{NO}_{x}$ budget (Davidson and Kingerlee 1997). Using an empirical model, Yienger and Levy (1995) identified agricultural soils, grassland and tropical rain forest as the largest sources of soil $\mathrm{NO}_{x}$, accounting for 41,35 and $16 \%$ of the global annual soil $\mathrm{NO}_{x}$ budget, respectively. With 
predicted increases in $\mathrm{N}$ fertilizer use, the agricultural source of atmospheric $\mathrm{NO}_{x}$ is likely to increase and to contribute to more than $50 \%$ of the global soil emissions in the future (Yienger and Levy 1995).

In arable soils, nitric oxide (NO) is predominantly produced by nitrification and denitrification, both microbial pathways, and through the chemical decomposition of $\mathrm{HNO}_{2}$. Nitrification is the oxidation of $\mathrm{NH}_{4}^{+}$to $\mathrm{NO}_{3}^{-}$, whereas denitrification is the anaerobic reduction of $\mathrm{NO}_{3}^{-}$to gaseous forms of $\mathrm{N}$ (Bremner and Blackmer 1978). Nitric oxide is a by-product of the nitrification pathway, and the typical yield of $\mathrm{NO}$ in well aerated soil ranges from $1 \%$ to $4 \%$ of the $\mathrm{NH}_{4}^{+}$oxidized (Hutchinson and Brams 1992). Nitric oxide is also a direct intermediate of the denitrification pathway, and its net release is greatly influenced by its gas phase diffusivity in the soil, and its consumption by denitrifiers. Under anaerobic conditions, the probability of NO being consumed by the denitrifying community is highly enhanced. Many authors emphasized that nitrification seems to be the dominant process of $\mathrm{NO}$ emission for many soils (Bollmann et al. 1999; Dunfield and Knowles 1999; Godde and Conrad 2000). Ammonium-based fertilizers increase NO emissions both by stimulating $\mathrm{NO}$ production by nitrification, and by decreasing NO consumption.

In general, the magnitude of soil NO production depends on the rates of nitrification and denitrification, and on soil diffusion properties. The most important regulating factors include soil mineral nitrogen content, soil temperature, and those soil variables which control gaseous diffusivity: soil texture, bulk density, and water content. These different factors are in turn largely influenced by agricultural management practices such as tillage and timing of fertilizer applications.

The large uncertainties in the soil NO source budget result from the paucity of available measurements encompassing the whole duration of crops' growing periods, along with the simplified approaches used to model the processes responsible for NO production in various ecosystems. On a global scale, most models are currently based on a mean emission factor depending on the considered biome, which results in most cases from inventory of literature review (Potter et al. 1996; Davidson and Kingerlee 1997; Davidson et al. 1998; Ludwig et al. 2001). These emission factors may be linked to environmental variables such as soil temperature or humidity (Williams et al. 1992; Yienger and Levy 1995; Potter et al. 1996; Stohl et al. 1996). In most cases, NO fluxes are proportional to an exponential function of the soil temperature, with the proportionality factor depending on the type of biome considered. This factor is generally constant, except for arable land where it varies as a function of nitrogen fertilizer inputs.

When applied to arable land, these kind of models suffers severe limitations: they do not take into account climatic context, soil characteristics, or agricultural management (irrigation and tillage timings, quantity and form of nitrogen inputs).

The first objective of this paper was to propose a consistent database of NO fluxes measured on the field scale during several months under maize and wheat crop. The second was to relate $\mathrm{NO}$ emissions to nitrification rates using laboratory and field measurements.

\section{Material and methods}

\section{Site description}

Experiments were carried out on a 1-ha field at Grignon in the Paris (France) area $\left(48.9^{\circ} \mathrm{N}\right.$, $1.95^{\circ} \mathrm{E}$ ). The soil was a silt loam, with $33 \%$ clay and $16 \%$ sand in the surface, and an alkaline $\mathrm{pH}$ $(\mathrm{pH}$ in water of 8.3). Surface organic carbon content was $21.78 \mathrm{~g} \mathrm{~kg}^{-1}$, and $\mathrm{C} / \mathrm{N}$ ratio was 12.6 . In the top $15 \mathrm{~cm}$, soil bulk density was $1.21 \mathrm{~g} \mathrm{~cm}^{-3}$ for the wheat crop, and $1.13 \mathrm{~g} \mathrm{~cm}^{-3}$ for the maize crop.

The field was divided into two parts. One was sown with wheat on October 10, 2001 and fertilized with $50 \mathrm{~kg} \mathrm{~N}^{-1}$ as UAN solution $(50 \%$ as urea $+50 \%$ as $\mathrm{NH}_{4} \mathrm{NO}_{3}$ ) on March 4 and $80 \mathrm{~kg}$ $\mathrm{N} \mathrm{ha}^{-1}$ as $\mathrm{NH}_{4} \mathrm{NO}_{3}$ granules on April 3, 2002. The wheat (Triticum aestivum L.) was harvested on July 22, 2002. The second part was sown with maize (Zea mays L.) on April 17, 2002, fertilized with $140 \mathrm{~kg} \mathrm{~N} \mathrm{ha}^{-1}$ as UAN solution on April 25, and harvested on October 21.

The major climatic variables (including solar radiation, air and soil temperature, wind speed, air and soil humidity, rainfall) were continuously recorded with a data logger (Campbell Scientific, CR10, Sherpard UK), during the entire 
experiment (October 2001 to October 2002). The data logger and the different sensors were located between the two parts of the field, so that soil temperature and moisture probes could be placed under the two crops using the same data logger. Soil water content was continuously recorded using TDR (Tme Domain Reflectrometry, CS615 Campbell Scientific) in the top $15 \mathrm{~cm}$.

Every 2 weeks, soil samples were taken to measure mineral nitrogen content $\left(\mathrm{NO}_{3}{ }^{-}, \mathrm{NH}_{4}{ }^{+}\right)$. Plant status was also characterized (LAI, dry matter, total nitrogen content) during the entire growing period.

Figure 1 shows the variation of the leaf area index for the two crops.

\section{NO flux measurements}

NO fluxes were measured during 10 months every 2 weeks using 3 manual closed chambers for each fields, and continuously with a wind tunnel (Lockyer 1984) in the 2 months following nitrogen fertilization.

\section{Manual chamber}

The manual chambers were made of stainless steel to avoid all surface interactions with nitrogen oxide gases. The chambers were square with a volume of 821 , and a ground area of $0.25 \mathrm{~m}^{2}$. They were attached to a stainless steel frame inserted in the soil to a depth of $10 \mathrm{~cm}$. The air inside the chambers was mixed using a Teflon fan. Gas analysers and data logging systems (Campbell Scientific CR23) were housed in a nearby mobile laboratory. During each sequence of measurements, air was pumped from the chamber to the gas analysers at a flow rate of $21 \mathrm{~min}^{-1}$ through Teflon tubing ( $1 / 4^{\prime \prime}$ ID). $\mathrm{NO}$ and $\mathrm{NO}_{2}$ concentra-

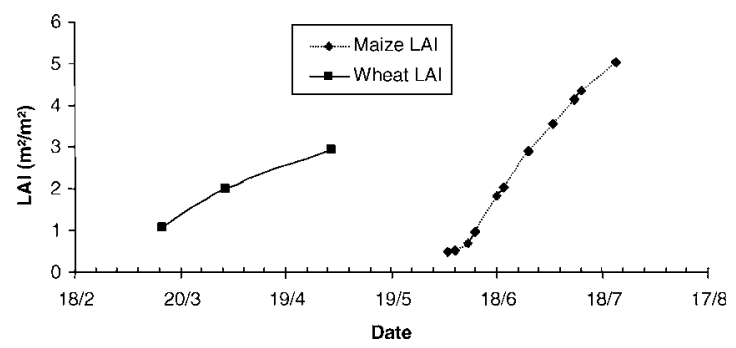

Figure 1. Leaf area index (LAI) of the wheat and maize crops. tions were measured by chemiluminescence's analyser fitted with a molybdenum converter (Thermo-Environmental Instruments Inc.; model 42 CTL, Franklin Massachusetts). The detection limit of these analysers was about 50 ppt.

NO fluxes were calculated from the maximum slope of the NO concentration (C) curve over time. The slopes $(\mathrm{dC} / \mathrm{dt})$ were estimated with a time step of $60 \mathrm{~s}$, and the overall integrating time was $300 \mathrm{~s}$. Fluxes were estimated according to the following equation:

$$
F=\operatorname{Max}\left(\frac{d C}{d t}\right) \frac{V}{S}
$$

where $V$ is the chamber volume (82 1), and $S$ the area covered by the chamber $\left(0.25 \mathrm{~m}^{2}\right)$.

For the maize crop, the frames were inserted between the rows. For the wheat, we cut the plants that were too tall to fit inside the chambers.

\section{Wind tunnel}

Wind tunnels have been widely used to measure ammonia volatilization, but not yet to estimate $\mathrm{NO}_{x}$ and $\mathrm{O}_{3}$ exchanges above the soil surface. Their performance has largely been discussed (Loubet et al. 1999a, b). The basic principle of this technique is to assess the difference between the input and the output concentration of a gas in the tunnel. The system boundaries for calculating this mass balance are the experimental area (maize or wheat crop), the cover of the wind tunnel, and the inlet and outlet cross-sections of the cover (Figure 2). The mass conservation of the gas then reads:

$$
F=\frac{Q\left(C_{o}-C_{i}\right)}{S}
$$

where $F$ is the flux measured (ppb $\mathrm{m} \mathrm{s}^{-1}$ ), Q is the volumetric flow rate $\left(\mathrm{m}^{3} \mathrm{~s}^{-1}\right), \mathrm{S}$ the experimental area $\left(\mathrm{m}^{2}\right)$, and $\mathrm{C}_{o}$ and $\mathrm{C}_{i}$ the mean output and input gas concentrations of the gas (ppb). The wind tunnel was constructed according to the system proposed by Lockyer (1984). The experimental area consisted of $1 \mathrm{~m}^{2}$ surface $(0.5 \mathrm{~m} \times 2 \mathrm{~m})$, covered with an inverted $U$ polycarbonate sheet, $5 \mathrm{~mm}$ thick, with a $85 \%$ transmittance for solar radiation between 420 and $750 \mathrm{~nm}$. Note that the cover blocked wavelengths lower that $420 \mathrm{~nm}$, preventing the photolysis of $\mathrm{NO}_{2}$ known to occur in the $300-420 \mathrm{~nm}$ range. Ventilation was provided by a large fan, whose speed was adjusted to yield a flow 


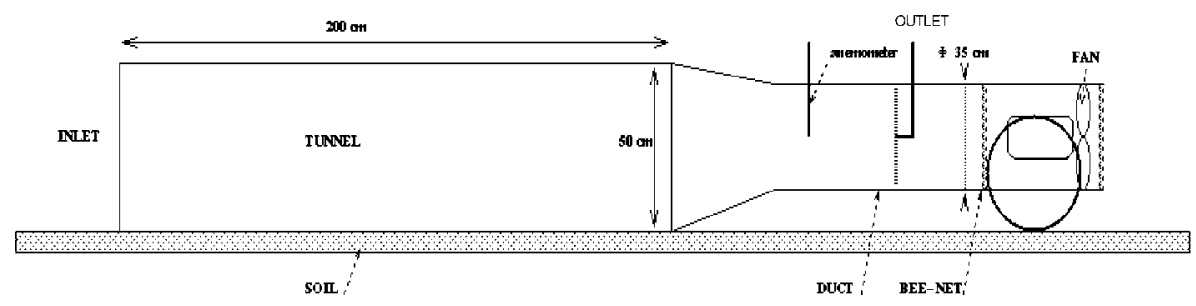

Figure 2. Wind tunnel design.

rate of $0.255 \mathrm{~m}^{3} \mathrm{~s}^{-1}$. The fan was connected to the tunnel through a $0.35 \mathrm{~m}$ diameter cylindrical duct. The duct design was optimized to induce uniform wind speed and gas concentrations over the duct section, which was $0.245 \mathrm{~m}$ in diameter (Loubet et al. 1999a, b). A hot wire anemometer and an inlet tube were placed in the duct to measure $\mathrm{Q}$ and $\mathrm{C}_{o}$. In order to retain local source of pollutants, a vertical $1.5 \mathrm{~m}$ tall shaft was set in front of the tunnel. Inlet air of the wind tunnel then came from the $1.5 \mathrm{~m}$ height.

$\mathrm{NO}$ and $\mathrm{NO}_{2}$ concentrations were measured with the same chemiluminescence analyser. $\mathrm{O}_{3}$ concentrations were measured by an UV absorption analyser (Model O3 41M, Environnement SA; Poissy, France), with a detection threshold of $1 \mathrm{ppb}$.

\section{Laboratory data}

Soil was sampled from the $0-15 \mathrm{~cm}$ layer in 10 replicates, prior to seeding in October 2001. The replicate samples were pooled, dried to about $2 \%$ moisture content $(\mathrm{w} / \mathrm{w})$, sieved through a $1 \mathrm{~mm}$ mesh and stored at $4{ }^{\circ} \mathrm{C}$ before use.

Soil incubations were performed at $20^{\circ} \mathrm{C}$ under dark conditions in $37 \mathrm{ml}$ air-tight flasks. During the incubations, each flask contained the equivalent of $5 \mathrm{~g}$ of dry soil. The gradient of nitrification rate (6 nitrification rates with 3 replicates each) was obtained by adding different amounts of water to soil samples, which resulted in soil moisture levels varying from 9 to $27 \%$ (w/w). Ammonium $\left(\mathrm{NH}_{4}{ }^{+}\right)$was added as ammonium sulphate at the same time as water to produce a soil concentration of ca. $0.40 \mathrm{mg} \mathrm{N} \mathrm{g}^{-1}$ soil, known as non-limiting for the nitrification process. Soil incubations were performed in the surrounding atmosphere. Nitrification rates were determined from the increase in $\left(\mathrm{NO}_{2}{ }^{-}+\mathrm{NO}_{3}{ }^{-}\right)-\mathrm{N}$ occurring in the soil during a 9-day period of incubation (Garrido et al. 2002). Mineral $\mathrm{N}$ was extracted with $1 \mathrm{~m} \mathrm{KCl}$ solution (soil:solution ratio of 1:5) at time zero and after 2, 5,7 , and 9 days of incubation. Nitrate and nitrite concentrations were determined by colorimetric assay using the Griess-Ilosvay reaction (Keeney and Nelson 1982).

\section{Modelling}

In the modelling approach, we focused on the nitrification pathway and computed NO production directly from the nitrification activity, using a linear relationship. The equation reads:

$$
\mathrm{NO}=a N_{\mathrm{i}}
$$

where $N_{\mathrm{i}}$ is the actual nitrification rate $\left(\mathrm{mg} \mathrm{NO} \mathrm{NO}_{3}-\mathrm{N}\right.$ $\mathrm{kg} \mathrm{soil}^{-1} \mathrm{day}^{-1}$ ), and NO is the corresponding NO production rate (mg NO-N kg soil ${ }^{-1}$ day $^{-1}$ ), and $a$ is a unit less coefficient. The nitrification rate, $\mathrm{N}_{i}$, is calculated as the product of three functions expressing the controls by soil humidity, temperature and ammonium content (Hénault et al. 2004):

$$
N_{\mathrm{i}}=N_{\mathrm{w}} N_{\mathrm{T}} N_{\mathrm{NH}_{4}}
$$

where $N_{\mathrm{w}}\left(\mathrm{mg} \mathrm{NO}-\mathrm{N} \mathrm{kg} \mathrm{soil}{ }^{-1} \mathrm{day}^{-1}\right)$ is the nitrification response to soil water content. It was determined in the above-described laboratory experiment under controlled conditions (temperature set at $20{ }^{\circ} \mathrm{C}$ ), with a non limiting ammonium supply, and a water content varying between 9 and $27 \%(w / w)$. A linear relationship was observed between nitrification rate and soil water content, viz.:

$$
N_{\mathrm{w}}=b W_{\mathrm{c}}+c
$$

where $W_{\mathrm{c}}$ is the gravimetric water content ( $\mathrm{g}$ water $\mathrm{g}$ soil $^{-1}$ ), b and $\mathrm{c}$ are regression coefficients. 
$N_{\mathrm{T}}$ is the nitrification response to soil temperature. We used the following relationship from Linn and Doran (1984):

$$
N_{\mathrm{T}}=\exp \left[\frac{(T-20) \operatorname{Ln}(2.1)}{10}\right]
$$

where $T$ is the soil temperature $\left({ }^{\circ} \mathrm{C}\right)$. This function was adjusted to give a value of unity at $20{ }^{\circ} \mathrm{C}$.

Lastly, $\mathrm{N}_{\mathrm{NH}_{4}}$ is the relationship between nitrification rate and ammonium content. We used the following Michaelis kinetics equation:

$$
N_{\mathrm{NH}_{4}}=\frac{\left[\mathrm{NH}_{4}^{+}\right]}{k m+\left[\mathrm{NH}_{4}^{+}\right]}
$$

where $\left[\mathrm{NH}_{4}{ }^{+}\right]$is the soil ammonium content ( $\mathrm{mg} \mathrm{N} \mathrm{kg} \mathrm{soil}{ }^{-1}$ ) and $\mathrm{km}$ is the half-saturation constant (mg N kg soil ${ }^{-1}$ ), calculated for different soil water contents (Focht et al. 1978). In the literature, there are few experimental determinations of $\mathrm{km}$, and a wide range of values has been reported, varying from $<1$ to $>50 \mathrm{mg} \mathrm{N} \mathrm{kg} \mathrm{soil}{ }^{-1}$ (Bosatta et al. 1981).

Thus, we fitted the $\mathrm{km}$ coefficient using the measured soil moisture, temperature and ammonium data measured in the topsoil layer $(0-15 \mathrm{~cm})$ under the wheat and maize crops. Following nitrogen fertilization, when all the fertilizer nitrogen could be considered as dissolved and when plant nitrogen uptake could be neglected, we used equations (4), (5), (6), and (7) to estimate the daily nitrification rate between the soil sampling dates. These periods run from April 30 to May 25 for the wheat, and from May 7 to June 6 for the maize. Each day, the daily calculated nitrification rate was subtracted from the current ammonium pool to calculate soil $\mathrm{NH}_{4}{ }^{+}$content for the following day. This calculation was repeated until the date of the next soil ammonium content sampling. The $\mathrm{km}$ value was then adjusted to match the calculated and observed soil ammonium content.

\section{Results and discussion}

\section{Seasonal dynamics under wheat and maize crops}

The NO fluxes measured with the chamber method on the wheat from November 2001 to October 2002 are shown in Figure 3. The 44 data varied between 0.3 and $37.1 \mathrm{ng} \mathrm{NO}-\mathrm{N} \mathrm{m}^{-2} \mathrm{~s}^{-1}$, and had a mean value of $7.4 \mathrm{ng} \mathrm{NO}-\mathrm{N} \mathrm{m}^{-2} \mathrm{~s}^{-1}$ for the whole campaign. Emissions were maximum after the two nitrogen fertilizer inputs (on March 8 and April 3), and remained significantly higher than the background emissions for about 3 weeks each time. Outside these periods, emissions remained at background level of a few ng NO-N m $\mathrm{m}^{-2} \mathrm{~s}^{-1}$. For the second fertilization, the largest emissions occurred only 20 days after application. This time delay could be explained easily by a lack of rainfall over these 20 days (Figure 3a). The nitrogen fertilizer applied was thus not readily incorporated in the soil. Overall, NO emissions under wheat were higher after the second fertilization compared to the first one, despite the nitrogen input to the soil being only effective 3 weeks after application. Indeed, part of the nitrogen could have been lost by volatilization during the dry period, which was unfavourable to NO production.

Regarding the first fertilization, the cumulative losses of nitrogen as $\mathrm{NO}$ gas over 1 month was equivalent to $200 \mathrm{~g} \mathrm{NO}-\mathrm{N} \mathrm{ha}{ }^{-1}$ (from March 8 to April 8), which represents about $0.4 \%$ of the nitrogen input. As for the second input, the loss total was $500 \mathrm{~g}$ NO-N ha ${ }^{-1}$, representing about $0.6 \%$ of the input. For the second estimate, losses were cumulated only after the first rainfall event when the fertilizer was incorporated into the soil, i.e. from April, 18 to May 18. In terms of nitrogen balance over the 10 months of measurements, the NO-N loss was estimated at $1.4 \mathrm{~kg} \mathrm{~N}^{-1}$ for the wheat crop, which corresponds to $1 \%$ of the total $\mathrm{N}$-inputs. At that point we must nevertheless distinguish NO losses due to fertilization from those due to the background mineralization of soil organic nitrogen. For the 300 days of wheat growth, we considered that $\mathrm{N}$ fertilizer was effectively present in soil only during 70 days (from March 8 to May 18), corresponding to a mean NO flux of $11 \mathrm{~g}$ NO-N ha ${ }^{-1} \mathrm{~d}^{-1}$. Outside this period, the background emissions averaged $2.6 \mathrm{~g}$ NO$\mathrm{N} \mathrm{ha}{ }^{-1} \mathrm{~d}^{-1}$. Thus, if we subtract the latter contribution to the 10 months NO emissions, we find that only $0.45 \%$ of the fertilizer was emitted as NO.

The NO fluxes from the maize crop were measured from April 29 to October 4, using the chamber technique. Fluxes were sampled on 21 dates, and varied between 1.3 and $245.3 \mathrm{ng}$ NO$\mathrm{N} \mathrm{m}^{-2} \mathrm{~s}^{-1}$, with a mean of $56.3 \mathrm{ng} \mathrm{NO}-\mathrm{N} \mathrm{m}^{-2} \mathrm{~s}^{-1}$ over the whole campaign (Figure 4). In terms of nitrogen balance, the NO-N loss was estimated at $3.8 \mathrm{~kg} \mathrm{~N} \mathrm{ha}^{-1}$ over the 6 months of measurements 

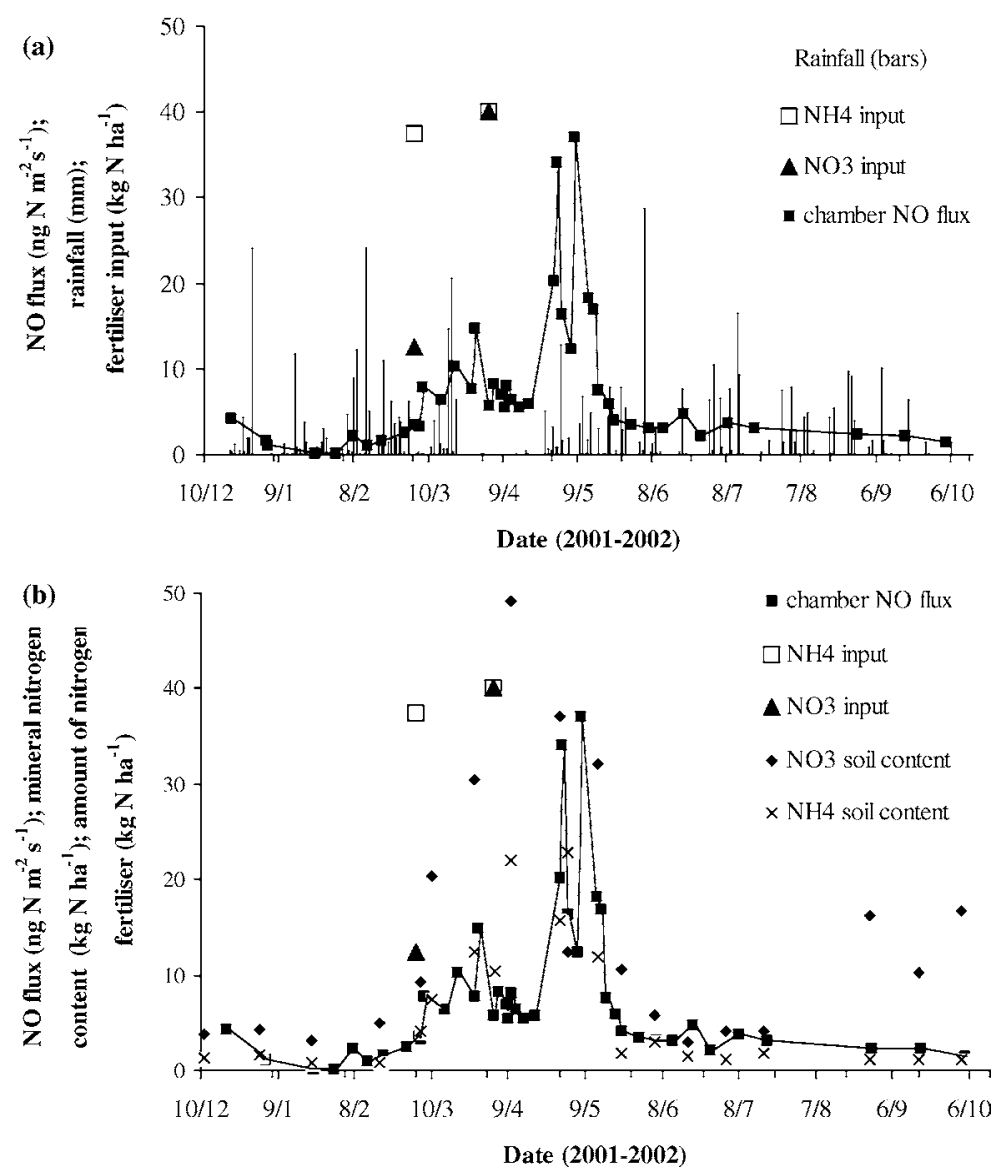

Figure 3. (a) Mean daily NO fluxes measured with chamber method and rainfall during the whole growing period of the wheat crop. (b) Mean daily NO fluxes (chamber method) with nitrate and ammonium contents in the $0-15 \mathrm{~cm}$ layer during whole growing period of wheat crop. The mean bulk soil density was 1.21 for this layer. The fertilizer amounts as ammonium or nitrate are also showed.

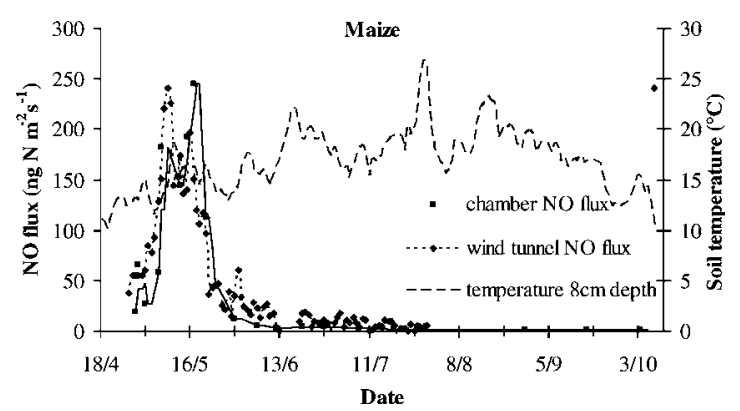

Figure 4. Mean daily fluxes monitoring with chamber and wind tunnel method on maize crop compared with the variations of the soil temperature.

for maize crop, corresponding to $2.6 \%$ of the total $\mathrm{N}$ input. As for the wheat, we distinguished the fertilizer NO losses, from these due to the background mineralization of soil organic N-matter. Over the 187 days of the plant growth, we considered that $\mathrm{N}$ fertilizer was effective only during
38 days (from April 25 to June 2), corresponding to a mean NO flux of $86.5 \mathrm{~g} \mathrm{~N}-\mathrm{NO} \mathrm{ha}^{-1} \mathrm{day}^{-1}$. Outside this period, the background emission was $2.3 \mathrm{~g} \mathrm{NO}^{\mathrm{N} \mathrm{ha}}{ }^{-1} \mathrm{day}^{-1}$. If we subtract the latter contribution to the $\mathrm{NO}$ emission, we consider that only $2.3 \%$ of the $\mathrm{NO}$ emission was due to fertilizer application. This ratio is about five times higher than that for the wheat crop. For both crops, the amounts of nitrogen lost as NO gas were consistent with literature data (Skiba et al. 1992, 1997; Davidson and Kingerlee 1997; Veldkamp and Keller 1997; Simpson et al. 1999).

\section{Comparison between wind tunnel and chamber measurements}

On maize, NO emissions were also monitored every $1 / 4 \mathrm{~h}$ from April 29 to July 28 using a wind 
tunnel. Figure 4 shows the mean daily NO emissions obtained with this technique. We observed a good similarity among the emissions, both in magnitude and in variation between the emissions measured by the chamber and by the wind tunnel technique. With the latter technique, the mean value over the whole period was $44.6 \mathrm{ng}$ NO$\mathrm{N} \mathrm{m}^{-2} \mathrm{~s}^{-1}$, with a maximum value of $240.7 \mathrm{ng}$ NO-N m${ }^{-2} \mathrm{~s}^{-1}$. Small differences between the two methods could be explained by the fact that the wind tunnel method disturbs emissions by modifying the local turbulence and soil humidity. The sheet of polycarbonate above the enclosed soil area was an obstacle to rainfall, and could alter soil humidity. After each rainfall event and to avoid any water deficit, we irrigated the soil. Nevertheless, the timing of irrigation was not totally equivalent to the rainfall, and could explain the differences observed especially on May 9 and 17. The daily emissions were also not estimated on the same time basis. For the wind tunnel, it was a truly mean daily value while for the chamber method, the values were obtained during the morning or the afternoon only.

\section{Temperature and rainfall effects}

The quarter-hourly fluxes measured with the wind tunnel (Figure 5) indicated a large diurnal variation of emissions, which paralleled the variations in soil surface temperature. We observed an exponential dependence between these two variables. This dependence was quantified over a particular week, from May 13 to May 19.
Instantaneous fluxes were divided by their mean daily value to take into account the variation in $\mathrm{NO}$ emissions resulting from other environmental control factors which varied on a larger time scale (i.e. soil nitrogen or water content). We obtained the following relationship between the two variables:

$$
\begin{aligned}
\text { Flux }_{\mathrm{no}} & =0.270( \pm 0.010) \exp [0.068( \pm 0.002) T] \\
R^{2} & =0.50
\end{aligned}
$$

where $T$ is the surface soil temperature $\left({ }^{\circ} \mathrm{C}\right)$ in the tunnel, and Flux $x_{\text {no }}$ the normalized flux. This relationship was established with soil temperatures in the range of 10 to $30^{\circ} \mathrm{C}$. The temperature dependence of the NO fluxes is consistent with the previous estimates (Williams et al. 1992), in that it corresponds to a $\mathrm{Q}_{10}$ value of about 2.1. It is similar to the value reported by Linn and Doran (1984), and used in the NO model here. The uncertainty of the emissions' dependence with temperature was linked to the asymmetry of $\mathrm{NO}$ emission response to temperature. For all days, the NO flux response was more important during the rising temperature phase in the morning than during the decreasing phase in the afternoon.

On a seasonal time-frame, the differences in NO response between the two fertilization applications on the wheat could be partly explained by soil temperature. From March to May, mean soil temperature at the $8 \mathrm{~cm}$ depth indeed increased from $10.5^{\circ} \mathrm{C}$ to $13.7^{\circ} \mathrm{C}$. The use of Equation (8) indicates that this $3.2^{\circ} \mathrm{C}$ difference should induce a $20 \%$ relative increase in the soil NO production rates, which is in agreement with the difference in

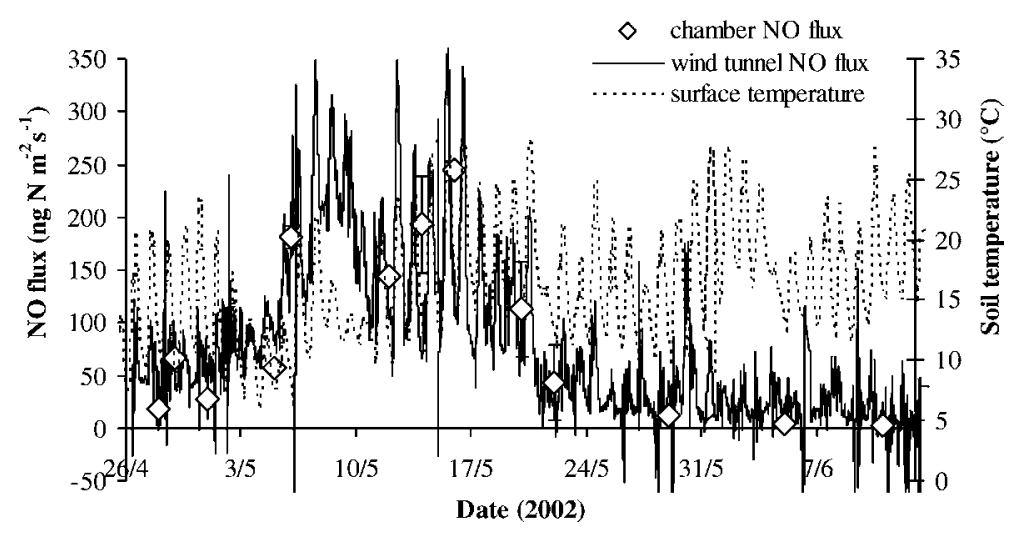

Figure 5. Quarter hourly NO fluxes measured using the wind tunnel with surface soil temperature on maize crop. 
cumulative losses after the two $\mathrm{N}$ applications. The same applies when comparing the wheat and maize crops. During the month following the $\mathrm{N}$ application on maize (from May 4 to 28), mean soil temperature at the $8 \mathrm{~cm}$ depth was $14.7^{\circ} \mathrm{C}$, which favoured larger $\mathrm{NO}$ emissions.

Rain was generally observed to stimulate $\mathrm{NO}$ emissions, with higher fluxes being recorded after all rainfall events. This is in accordance with numerous studies (Johansson and Sanhueza 1988; Williams et al. 1992). Rainfall also had an indirect effect, in that it dissolved fertilizer granules, thereby making ammonium available to soil nitrifiers and preventing ammonia volatilization. This appears for instance on April 26, when rainfall induced $\mathrm{NO}$ emissions to peak two weeks after fertilizer application on the wheat (Figure 3a).

The soil water content during the experiments remained quite low. Based on soil bulk density values measured in each field, these water contents translated as WFPS (water-filled pore space) values generally ranging from 20 to $60 \%$ (Figure 6). Under these conditions denitrification rates were probably very low and nitrification can be
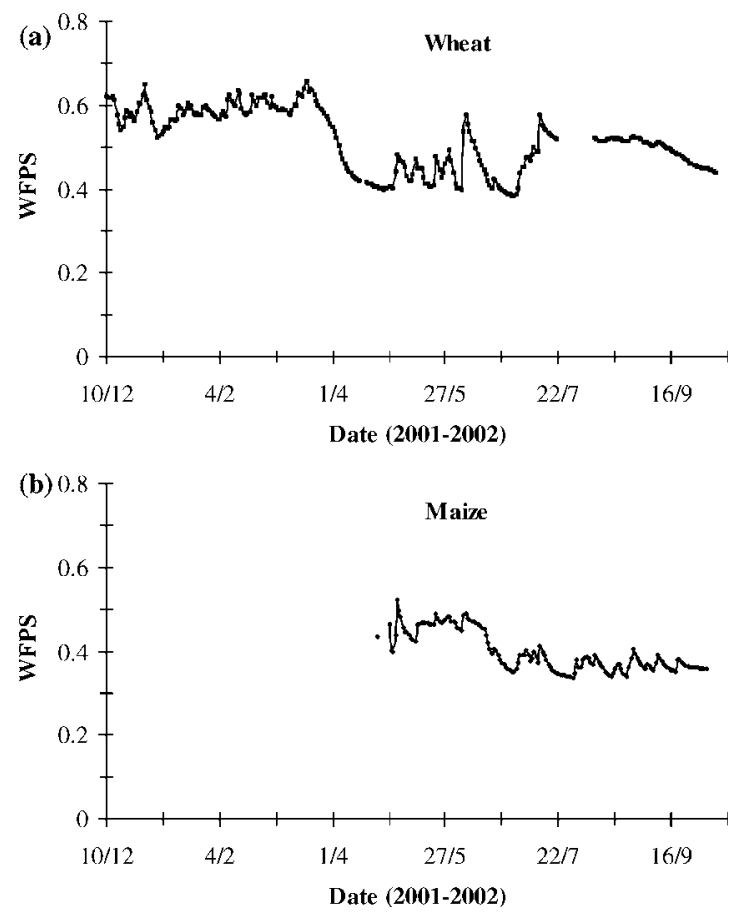

Figure 6. Water-filled spore space (WFPS) for wheat (a) and maize (b) crops in the $0-15 \mathrm{~cm}$ layer. considered as the main process involved in $\mathrm{NO}$ production.

\section{Management effects}

Beyond climate-induced effects, differences in the response to nitrogen fertilizer application might be related to timing as well as to the form of fertilizer applied. For the wheat crop, the loss as NO during the month after the first application was estimated at $200 \mathrm{~g} \mathrm{~N} \mathrm{ha}^{-1}$, while it was $500 \mathrm{~g} \mathrm{~N} \mathrm{ha}^{-1}$ for the second input. The difference in $\mathrm{N}$ losses could be explained by a difference in soil temperature $(20 \%)$, by the quantity of $\mathrm{N}$ applied $\left(50 \mathrm{~kg} \mathrm{~N} \mathrm{ha}^{-1}\right.$ and $80 \mathrm{~kg} \mathrm{~N} \mathrm{ha}^{-1}$ for the first and second fertilization, respectively), but also by the stage of plant development. Indeed, the first fertilization corresponded to the onset of spring growth for the wheat plants. Their LAI increased from 1 to $2 \mathrm{~m}^{2} \mathrm{~m}^{-2}$ over the 18 days time interval running, from March 15 to April 2 (Figure 1). After the second application, the growth rate of LAI was approximately halved, rising from 2 to 2.9 between April 2 and May 2. Immediately after the first $\mathrm{N}$ application, the $\mathrm{N}$ needs of plants were thus higher, leaving less $\mathrm{N}$ available to the microorganisms responsible for NO formation. This could explain the lower emissions of NO for this period.

Similarly, the relative differences in NO emissions between the maize and wheat crops may be linked to the timing of fertilizer management with regard to plant development. Application of mineral nitrogen to bare soil, as was the case for the maize crop, is certainly not a practice likely to reduce NO emissions. This makes applied nitrogen fully available to nitrifiers or denitrifiers, and leads to enhanced NO emission. However, it is necessary to prevent leaf and plant damage that may occur when applying liquid forms of fertilizer at a later stage. The differences in $\mathrm{NO}$ emission rates measured simultaneously on the two crops from April 25 to June 2 were quite large: the NO fluxes averaged $16 \mathrm{ng}$ NO-N m${ }^{-2} \mathrm{~s}^{-1}$ for the wheat and $100 \mathrm{ng}$ NO-N m${ }^{-2} \mathrm{~s}^{-1}$ for the maize. Because the comparison was carried out on the same field and during the same time period, these differences should be ascribed to differences in soil mineral nitrogen content. These differences resulted in turn from the doses applied to the crops: $140 \mathrm{~kg}$ 
$\mathrm{N}$ ha $^{-1}$ (with 105 as ammonium and 35 as nitrate) for the maize, and $80 \mathrm{~kg} \mathrm{~N}^{-1}$ (with 40 as ammonium and 40 as nitrate) for the second input for the wheat. Nevertheless, a large part of the emission from the two crops (factor of about 6) could certainly be explained by difference in plant nitrogen assimilation between the two crops.

These observations demonstrate the need to use a 'crop model' to quantify the different nitrogen fluxes in the soil (mineralization, immobilization, plant uptake,...) and their relative effects on the NO source.

Furthermore, the type of fertilizer used could induce differences in NO emission. For the wheat crop two different fertilizers were used. Since they resulted in similar doses of ammonium, totalling $37.5 \mathrm{~kg} \mathrm{NH}_{4}-\mathrm{N} \mathrm{ha}^{-1}$ and $40 \mathrm{~kg} \mathrm{NH}_{4}-\mathrm{N} \mathrm{ha}^{-1}$ for the first and second application respectively, we may conclude that ammonium nitrate results in higher NO emissions than the UAN solution. However, when we compare not only soil temperature between the two periods but also NO fluxes with $\mathrm{NO}_{3}$ and $\mathrm{NH}_{4}$ content variations in the top $15 \mathrm{~cm}$ (Figure 3b), it appears that NO emissions were driven by nitrification kinetics depending on ammonium content. With high nitrate content, we sometimes observed low NO emissions (on March 27 and April 11). In contrast, when the ammonium content fell to about one $\mathrm{mg}$ $\mathrm{N} \mathrm{kg} \mathrm{soil}{ }^{-1}$, NO emissions were always low. Furthermore, after crop harvest and incorporation of wheat straw in the soil by tillage, surface ammonium content was maintained at a low value of about one $\mathrm{kg} \mathrm{NH}_{4}-\mathrm{N}$ ha ${ }^{-1}$ while the nitrate content rose to $14 \mathrm{~kg} \mathrm{NO}_{3}-\mathrm{N}^{-1}$ in October as a result of the mineralization of crop residues. Surprisingly these high levels of nitrate did not lead to higher NO emissions and reinforced the belief that an important part of the NO emissions resulted at first from nitrification. This last conclusion is reinforced by the maize crop observations. There, the quantity applied in a single time was high (140 $\mathrm{kg} \mathrm{N} \mathrm{ha}^{-1}$ ), but the high emissions of NO could be linked to the form of the UAN solution used. If we consider that the major part of NO emission occurred by nitrification of the fertilizer, then the UAN solution favours largest NO emissions. This hypothesis is enhanced by analysis of NO emission versus soil nitrate and ammonia content (Figure 7). On the maize, the largest NO emissions lasted for about one month after fertilization until June 2. Thereafter (on June 6 and 18), the nitrate content in the $0-15 \mathrm{~cm}$ soil layer was still large, and resulted for a large part to the nitrification of the $105 \mathrm{~kg} \mathrm{NH}_{4}-\mathrm{N} \mathrm{ha}^{-1}$ applied on April 25. The rapid decrease in nitrate content after early May was then concomitant with plant growth.

\section{Modelling}

The relationship between nitrification rate and soil water content (Equation 5) was parameterized from the laboratory data as follows: $N_{\mathrm{w}}=0.8166$ $W \mathrm{c}-6.6868\left(R^{2}=0.96 ; n=5\right)$. It was obtained for a soil temperature of $20{ }^{\circ} \mathrm{C}$, a non-limiting $\mathrm{NH}_{4}{ }^{+}$ content, and for a soil water content between 9 and $27 \%(\mathrm{w} / \mathrm{w})$. These water contents are consistent with the soil water contents observed 'in situ'.

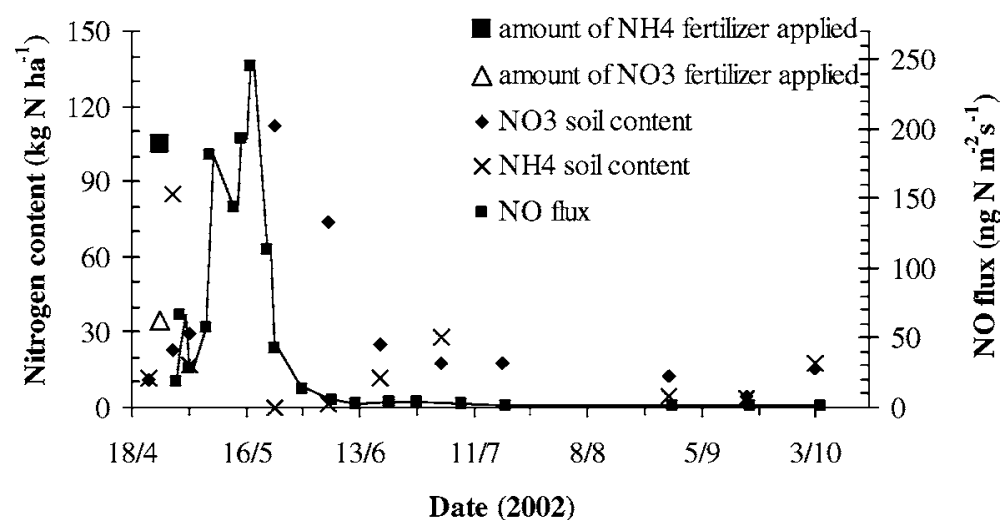

Figure 7. Mean daily NO fluxes (chamber method) with nitrate and ammonium contents in the 0-15 cm layer (bulk soil density of 1.13) during all growing period of wheat crop. The fertilizer amounts as ammonium or nitrate are also indicated. 

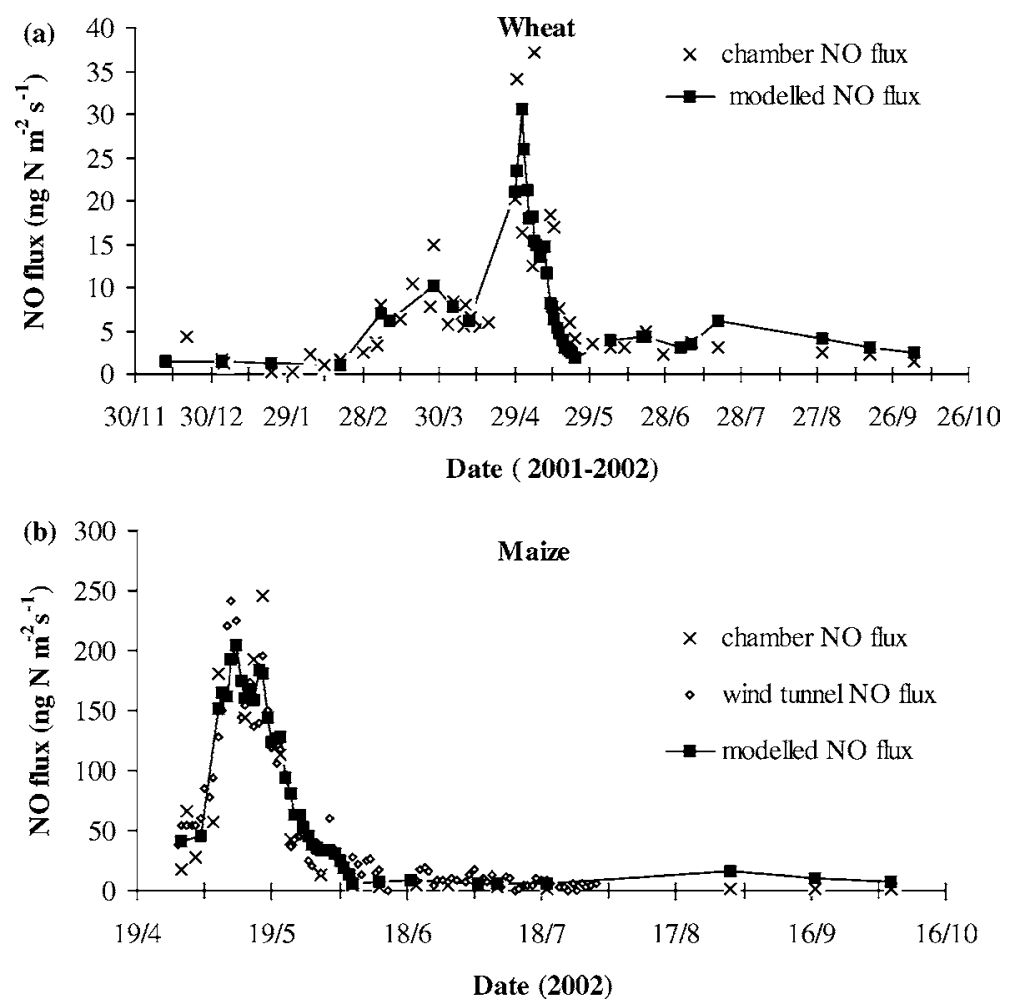

Figure 8. Comparison of modelled and measured NO fluxes (with tunnel or chamber methods) for wheat crop (a) and maize crop (b).

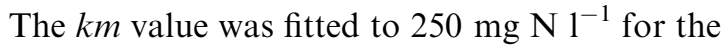
two crops. This value corresponds to $50 \mathrm{mg}$ $\mathrm{N} \mathrm{kg} \mathrm{soil}{ }^{-1}$ for a soil water content of $20 \%(\mathrm{w} / \mathrm{w})$.

Next, we estimated the coefficient $a$ appearing in Equation (3) by regressing the NO fluxes measured either with the wind tunnel or the chamber methods against the nitrification rates calculated above. We thereby assumed that only the top $15 \mathrm{~cm}$ of soil contributed to NO emissions. We obtained the following relationships:

$$
\mathrm{NO}=1.61( \pm 0.09) \% N_{\mathrm{i}} \quad R^{2}=0.90 ; n=14(10)
$$

for the maize crop with wind tunnel NO data

$$
\mathrm{NO}=1.90( \pm 0.11) \% N_{\mathrm{i}} \quad R^{2}=0.92 ; n=17
$$

for the maize crop with chamber NO data

$$
\mathrm{NO}=1.48( \pm 0.16) \% N_{\mathrm{i}} \quad R^{2}=0.53 ; n=27
$$

for the wheat crop with chamber NO data

where $\mathrm{NO}$ is $\mathrm{NO}$ emission rate ( $\mathrm{mg} \mathrm{NO}-\mathrm{N} \mathrm{kg} \mathrm{soil}{ }^{-1}$ ) and $N_{\mathrm{i}}$ the nitrification rate $\left(\mathrm{mg} \mathrm{NO}_{3}{ }^{-}-\mathrm{N} \mathrm{kg} \mathrm{soil}^{-1}\right)$.

For the three equations we observed a good correlation between these two variables, and the similar slope coefficients (around 1.6\%). The variability in the latter may be related to uncertainties of NO flux measurements at field scale, or to processes not considered in the $\mathrm{NO}$ emission algorithm (i.e. nitrogen uptake by plant, modification of soil $\mathrm{pH}$ by fertilizer $\mathrm{N}$, or $\mathrm{NO}$ emissions by denitrification). Figure 8 compares the measured and modelled NO emissions obtained for the wheat and maize crops. Modelled NO fluxes were estimated directly from the above regression equations.

Although the model only simulated NO production through the nitrification pathway, a good match between modelled and measured emissions was observed. It could be explained by the fact that conditions were seldom conducive to denitrification, since WFPS rarely exceeded the $60 \%$ threshold water conditions as reported by Parton et al. (2001) and Linn and Doran (1984), (Figure 6). Even when WFPS was above $60 \%$ (in late November, December and late February), other environmental conditions were not conducive to NO production, since soil mineral $\mathrm{N}$ and soil temperature were low. It is 
thus likely that NO production occurred mostly through nitrification.

Using the nitrification algorithm we tested the relative weights of the functions $N_{\mathrm{w}}, N_{\mathrm{T}}, N_{\mathrm{NH}_{4}}$ in NO production variability. Tables 1 and 2 give the relative contributions to the $\mathrm{NO}$ emission variation of these functions. Whatever the crop, the ammonium function $\mathrm{N}_{\mathrm{NH}_{4}}$ had a major contribution $(\sim 69 \%)$. It also appeared essential to determine the value of the half saturation coefficient $(\mathrm{km})$ with a high accuracy. An indirect estimation of this coefficient in the field, as was done here should be corroborated by laboratory experiments under controlled moisture and temperature conditions, involving a large gradient of $\mathrm{NH}_{4}{ }^{+}$concentrations. For the wheat crop, soil temperature was the second contributor to the NO variability, which may be explained by the wide range of soil temperatures experienced by the soil during the wheat growing season (from winter to summer). For the maize crop the contributions of the $N_{\mathrm{T}}$ and $N_{\mathrm{w}}$ function were similar ( $c a .14 \%$ ).

\section{Conclusions}

Our measurements highlighted a large dependence of $\mathrm{NO}$ emissions on mineral nitrogen fertilization: emissions were largest during the few days following nitrogen inputs, with mean daily rates greater than $300 \mathrm{~g} \mathrm{~N}^{-1} \mathrm{day}^{-1}$. A time lag of a few days was related to the kinetics of nitrogen fertilizer incorporation in the soil, which is linked to the occurrence of rainfall. The emissions measured on the maize field were higher than on the wheat field. The difference was linked to nitrogen input management. For the maize crop, nitrogen was applied before plant emergence, and was thus fully available to the soil micro-organisms responsible for NO production. The increase of $\mathrm{NO}$ emissions after the $\mathrm{N}$ inputs lasted about one month in both cases. After this period, we observed a return to background emissions of a few $g$ $\mathrm{N} \mathrm{ha}{ }^{-1} \mathrm{day}^{-1}$, as before fertilizer application. In terms of nitrogen balance, the $\mathrm{N}$ losses were esti-

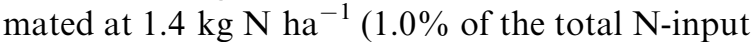
over the 10 months of measurements) for the wheat, and $3.8 \mathrm{~kg} \mathrm{~N} \mathrm{ha}^{-1}(2.6 \%$ of the $\mathrm{N}$-input over the 6 months of measurements) for the maize crop. The differences between the two crops could also be linked to the respective growing seasons of the plants. Indeed, a large correlation was observed between soil temperature and NO emissions, with a $\mathrm{Q}_{10}$ of about 2.1. This means emissions are likely to be higher with spring crops like maize.

Table 1. Contribution of the different functions $N_{\mathrm{T}}, N_{\mathrm{w}}$ and $N_{\mathrm{NH}_{4}}$, on the nitrification rate $\left(\mathrm{N}_{\mathrm{i}}\right)$ under maize.

\begin{tabular}{|c|c|c|c|c|c|}
\hline Date & $N_{\mathrm{T}}$ & $\mathrm{Nw}, \mathrm{mg} \mathrm{N} \mathrm{kg} \mathrm{soil}{ }^{-1} \mathrm{~d}^{-1}$ & $N_{\mathrm{NH}_{4}}$ & $\mathrm{~N}_{\mathrm{i}}, \mathrm{mg} \mathrm{N} \mathrm{kg} \mathrm{soil}{ }^{-1} \cdot \mathrm{d}^{-1}$ & $\mathrm{NO} \times 100, \mathrm{mg} \mathrm{N} \mathrm{kg} \mathrm{soil}{ }^{-1} \mathrm{~d}^{-1}$ \\
\hline $29 / 4$ & 0.603 & 12.738 & 0.147 & 1.128 & 0.866 \\
\hline $3 / 5$ & 0.618 & 15.184 & 0.133 & 1.245 & 1.309 \\
\hline $7 / 5$ & 0.573 & 11.972 & 0.598 & 4.105 & 8.617 \\
\hline $13 / 5$ & 0.696 & 12.738 & 0.488 & 4.324 & 6.861 \\
\hline $15 / 5$ & 0.750 & 12.893 & 0.443 & 4.287 & 9.176 \\
\hline $17 / 5$ & 0.972 & 12.834 & 0.392 & 4.885 & 11.677 \\
\hline $21 / 5$ & 0.975 & 12.719 & 0.279 & 3.459 & 5.391 \\
\hline $23 / 5$ & 0.754 & 13.310 & 0.217 & 2.180 & 2.024 \\
\hline $30 / 5$ & 0.706 & 13.032 & 0.100 & 0.921 & 0.603 \\
\hline $6 / 6$ & 0.771 & 13.700 & 0.016 & 0.168 & 0.229 \\
\hline $12 / 6$ & 0.857 & 12.755 & 0.017 & 0.182 & 0.128 \\
\hline $19 / 6$ & 1.177 & 9.831 & 0.020 & 0.227 & 0.178 \\
\hline $8 / 7$ & 0.872 & 9.017 & 0.021 & 0.162 & 0.126 \\
\hline $19 / 7$ & 0.899 & 8.147 & 0.022 & 0.159 & 0.082 \\
\hline $29 / 8$ & 0.851 & 9.834 & 0.050 & 0.419 & 0.092 \\
\hline $17 / 9$ & 0.704 & 8.085 & 0.050 & 0.285 & 0.070 \\
\hline $4 / 10$ & 0.560 & 6.951 & 0.054 & 0.210 & 0.060 \\
\hline$\sigma / m$ & 0.14 & 0.14 & 0.72 & & \\
\hline
\end{tabular}

The NO column corresponds to the values of NO emissions measured with the chamber method. The last line $(\sigma / m)$ corresponds to the coefficients of variation of the different terms $\left(N_{\mathrm{T}}, N_{\mathrm{w}}\right.$ and $\left.N_{\mathrm{NH}_{4}}\right)$. These three coefficients were normalized to give a sum of $100 \%$. They indicate the relative contribution of the three variables: soil temperature, humidity and ammonium content into the nitrification rate and also to the NO production variability. 
Table 2. Contribution of the different functions $N_{\mathrm{T}}, N_{\mathrm{w}}$ and $N_{\mathrm{NH}_{4}}$, on the nitrification rate $\left(\mathrm{N}_{\mathrm{i}}\right)$ under wheat.

\begin{tabular}{|c|c|c|c|c|c|}
\hline Date & $N_{\mathrm{T}}$ & $N_{\mathrm{w}}, \mathrm{mg} \mathrm{N} \mathrm{kg} \mathrm{soil}{ }^{-1} \mathrm{~d}^{-1}$ & $N_{\mathrm{NH}_{4}}$ & $N_{\mathrm{i}}, \mathrm{mg} \mathrm{N} \mathrm{kg} \mathrm{soil}{ }^{-1} \mathrm{~d}^{-1}$ & $\mathrm{NO} \times 100, \mathrm{mg} \mathrm{N} \mathrm{kg} \mathrm{soil}{ }^{-1} \mathrm{~d}^{-1}$ \\
\hline $12 / 12$ & 0.291 & 17.020 & 0.010 & 0.049 & 0.202 \\
\hline $3 / 1$ & 0.229 & 14.038 & 0.014 & 0.046 & 0.076 \\
\hline $23 / 1$ & 0.375 & 15.397 & 0.007 & 0.040 & 0.009 \\
\hline $19 / 2$ & 0.344 & 15.685 & 0.006 & 0.034 & 0.079 \\
\hline $7 / 3$ & 0.471 & 15.992 & 0.032 & 0.243 & 0.374 \\
\hline $11 / 3$ & 0.419 & 15.474 & 0.033 & 0.213 & 0.303 \\
\hline $28 / 3$ & 0.408 & 15.531 & 0.056 & 0.352 & 0.704 \\
\hline $5 / 4$ & 0.539 & 11.976 & 0.042 & 0.271 & 0.396 \\
\hline $11 / 4$ & 0.456 & 9.849 & 0.047 & 0.211 & 0.307 \\
\hline $29 / 4$ & 0.603 & 8.901 & 0.136 & 0.729 & 0.962 \\
\hline $30 / 4$ & 0.591 & 8.879 & 0.154 & 0.809 & 1.622 \\
\hline $2 / 5$ & 0.696 & 10.323 & 0.147 & 1.059 & 0.780 \\
\hline $6 / 5$ & 0.601 & 11.072 & 0.095 & 0.631 & 0.590 \\
\hline $7 / 5$ & 0.573 & 10.633 & 0.087 & 0.531 & 1.761 \\
\hline $13 / 5$ & 0.696 & 10.576 & 0.039 & 0.285 & 0.868 \\
\hline $15 / 5$ & 0.723 & 10.509 & 0.029 & 0.220 & 0.803 \\
\hline $17 / 5$ & 0.766 & 9.173 & 0.023 & 0.165 & 0.359 \\
\hline $21 / 5$ & 0.772 & 8.956 & 0.014 & 0.094 & 0.280 \\
\hline $23 / 5$ & 0.679 & 11.132 & 0.009 & 0.067 & 0.197 \\
\hline $6 / 6$ & 0.720 & 15.486 & 0.012 & 0.136 & 0.147 \\
\hline $19 / 6$ & 0.993 & 8.756 & 0.017 & 0.152 & 0.230 \\
\hline $20 / 6$ & 0.926 & 9.503 & 0.017 & 0.147 & 0.230 \\
\hline $8 / 7$ & 0.857 & 11.287 & 0.012 & 0.118 & 0.179 \\
\hline $19 / 7$ & 0.954 & 13.498 & 0.017 & 0.213 & 0.150 \\
\hline $29 / 8$ & 0.961 & 13.305 & 0.011 & 0.138 & 0.113 \\
\hline $17 / 9$ & 0.791 & 12.095 & 0.011 & 0.109 & 0.109 \\
\hline $4 / 10$ & 0.705 & 10.582 & 0.012 & 0.086 & 0.072 \\
\hline$\sigma / m$ & 0.20 & 0.13 & 0.66 & & \\
\hline
\end{tabular}

The NO column corresponds to the values of NO emissions measured with the chamber method. The last line $(\sigma / m)$ corresponds to the relative variability of the different terms $\left(N_{\mathrm{T}}, N_{\mathrm{w}}\right.$ and $\left.N_{\mathrm{NH}_{4}}\right)$. These three coefficients were normalized to give a sum of $100 \%$. They indicate the relative contribution of the three variables: soil temperature, humidity and ammonium content into the nitrification rate and also to the NO production variability.

Although the used simple model simulated only nitrification-mediated NO production, comparison between measured and modelled NO fluxes was very satisfactory, both in magnitude and in time variation after fitting the half saturation coefficient of the ammonium nitrification function. This good agreement could be explained by the low soil water contents prevailing under our experimental conditions, minimising the role of denitrification. Future investigations will be necessary to estimate NO production by denitrification in the laboratory under anaerobic conditions, and in situ with hydromorphic soils. Based on these results, the effect of fertilizer type on NO emission should also be a very interesting field of investigation. Future studies will also include the integration of this model for various crop managements and climates and extrapolation of these results to a global scale.

\section{Acknowledgments}

Support of this research was provided by the PNCA (Programme National de Chimie Atmospherique, INSU), and the GICC (Gestion et Impact des Changements Climatiques, MEED) national programs.

\section{References}

Bollmann A., Koschorreck M., Meuser K. and Conrad R. 1999. Comparison of two different methods to measure nitric oxide turnover in soils. Biol. Fert. Soils. 29: 104-110.

Bosatta E., Iskandar I.K., Juma N.G., Kruh G., Reuss J.O., Tanji K.K. and van Veen J.A. 1981. Statuts report on modelling of the processes. Soil microbiology. In: Frissel M.J. and van Veen J.A (eds), Simulation of nitrogen behaviour of soil-plant systems. Pudoc, Wageningen pp. 38-44. 
Bremner J.M. and Blackmer A.M. 1978. Nitrous oxide: emission from soils during nitrification of fertilizer nitrogen. Science 199: 295-296.

Davidson E.A. 1991. Fluxes of nitrous oxide and nitric oxide from terrestrial ecosystems. In: Rogers J.E. and Whitman W.B. (eds), Microbial Production and Consumption of Greenhouse Gases: Methane, Nitrous Oxides, and Halomethanes. American Society for Microbiology, Washington D.C. pp. 219-235.

Davidson E.A. and Kingerlee W. 1997. A global inventory of nitric oxide emissions from soils. Nutr. Cycl. Agroecosyst. 48: $37-50$.

Davidson E.A., Potter C.S., Schlesinger P. and Klooster S.A. 1998. Model estimates of regional nitric oxide emissions from soils of the South-eastern United States. Ecol. Appl. 8: 748759

Dunfield P.F. and Knowles R. 1999. Nitrogen monoxide production and consumption in an organic soil. Biol. Fert. Soils. 30: 153-159.

Focht D.D., Verstraete W. and Payne W.J. 1978. Methods for analysis of denitrification in soils. In: Nielsen D.R. and Mc Donald J.G. (eds), Nitrogen in the Environment. Vol. 2, SoilPlant-Nitrogen Relationships. Academic Press, New York pp. 433-523.

Garrido F., Hénault C., Gaillard H., Perez S. and Germon J.C. 2002. $\mathrm{N}_{2} \mathrm{O}$ and $\mathrm{NO}$ emissions by agricultural soils with low hydraulic potentials. Soil Biol. Biochem. 34: 559-575.

Godde M. and Conrad R. 2000. Influence of soil properties on the turnover of nitric oxide and nitrous oxide by nitrification and denitrification at constant temperature and moisture. Biol. Fert. Soils 32: 120-128.

Hénault C., Bizouard F., Laville P., Gabrielle B., Nicoullaud B., Germon J.C. and Cellier P. 2005. Predicting «in situ» soil $\mathrm{N}_{2} \mathrm{O}$ emission using a NOE algorithm and soil database. Global Change Biol. 11: 115-127.

Hutchinson G.L. and Brams E.A. 1992. NO versus $\mathrm{N}_{2} \mathrm{O}$ emissions from an $\mathrm{NH}_{4}{ }^{+}$amended Bermuda grass pasture. J. Geophys. Res.-D. 97: 9889-9896.

Johansson C. and Sanhueza E. 1988. Emission of NO from savanna soils during rainy season. J. Geophys. Res.-D. 93: 14193-14198.

Keeney D.R. and Nelson D.W. 1982. Nitrogen-inorganic form. In: Page A.L. (ed.), Methods of Soil Analysis. American Society of Agronomy, Madison, WI pp.643-698.

Linn D.M. and Doran J.W. 1984. Effect of water-filled pore space on carbon dioxide and nitrous oxide production in tilled and nontilled soils. Soil Sci. Soc. Am. J. 48: 1267-1272.

Lockyer D.R. 1984. A system for the measurement in the field of losses of ammonia through volatilization. J. Sci. Food Agric. 35: 837-848.
Loubet B., Cellier P., Flura D. and Génermont S. 1999a. An evaluation of the wind-tunnel technique for estimating ammonia volatilization from land: Part 1. Analysis and improvement of accuracy. J. Agric. Eng. Res. 72: 71-81.

Loubet B., Cellier P., Génermont S. and Flura D. 1999b. An evaluation of the wind-tunnel technique for estimating ammonia volatilization from land: Part 2. Influence of the tunnel on transfer processes. J. Agric. Eng. Res. 72: 83-92.

Ludwig J., Meixner F.X., Vogel B. and Förstner J. 2001. Soilair exchange of nitric oxide: an overview of processes, environmental factors, and modelling studies. Biogeochemistry 52: 225-257.

Parton W.J., Holland E.A., Del Grosso S.J, Hartman M.D., Martin R.E., Mosier A.R., Ojima D.S. and Schimel D.S. 2001. Generalized model for $\mathrm{NO}_{x}$ and $\mathrm{N}_{2} \mathrm{O}$ emissions from soils. J. Geophys. Res.-D. 106: 17403-17419.

Potter C.S., Matson P.A., Vitousek P.M. and Davidson E.A. 1996. Process modelling of controls on nitrogen trace gas emissions from soils worldwide. J. Geophys. Res.-D. 101: 1361-1377.

Simpson D., Winiwarter W., Börjesson G., Cinderby S., Ferreiro A., Guenther A., Hewitt C.N., Janson R., Khalil M.A.K., Owen S., Pierce T.E., Puxbaum H., Shearer M., Skiba U., Steinbrecher R., Tarrason L. and Öquist M.G. 1999. Inventorying emissions from nature in Europe. J. Geophys. Res.-D. 104: 8113-8152.

Skiba U., Hargreaves K.J., Fowler D. and Smith K.A. 1992. Fluxes of nitric and nitrous oxides from agricultural soils in a cool temperate climate. Atmos. Environ. 26: 2477-2488.

Skiba U., Fowler D. and Smith K.A. 1997. Nitric oxide emissions from agricultural soils in temperate and tropical climates: sources, controls and mitigation options. Nutr. Cycling Agroecosyst. 48: 139-153.

Stohl A., Williams E., Wotawa G. and KrompKolb H. 1996. A European inventory of soil nitric oxide emissions and the effect of these emissions on the photochemical formation of ozone. Atmos. Environ. 30: 3741-3755.

Veldkamp E. and Keller M. 1997. Fertilizer-induced nitric oxide emissions from agricultural soils. Nutr. Cycling Agroecosyst. 48: 69-77.

Williams E.J., Hutchinson G.L. and Fehsenfeld F.C. 1992. NO $x$ and $\mathrm{N}_{2} \mathrm{O}$ emissions from soil: natural sources of acid precursors, neutralizing compounds, and oxidants. Global Biogeochem. Cycl. 6: 351-388.

Yienger J.J. and Levy H. 1995. Empirical model of global soilbiogenic $\mathrm{NO}_{x}$ emissions. J. Geophys. Res.-D. 100: 1144711464. 